\title{
RELATO DE EXPERIÊNCIA: METODOLOGIA DE APRENDIZAGEM BASEADA EM PROJETO, EM CURSO DE GRADUAÇÃO A DISTÂNCIA
}

\author{
Michele Domingos Schneider ${ }^{1}$ \\ Elisa Netto Zanette ${ }^{2}$ \\ Nara Cristine Thomé Palácios Cechella ${ }^{3}$
}

\section{INTRODUÇÃO}

O desenvolvimento e popularização das Tecnologias da Informação e Comunicação (TICs) tem contribuído para a disseminação da Educação a Distância (EaD) no Brasil. É uma modalidade de ensino que tem crescido de forma acentuada nos últimos anos. Considerada, na atualidade, como a forma democrática de acesso ao ensino superior aos estudantes que, por diversos fatores, não podem frequentar 0 ensino presencial. Nesse contexto de expansão da EaD, são ainda perceptíveis, resistências a modalidade no ensino superior.

A EaD utiliza-se de recursos associados as TICs para potencializar os processos de ensino e aprendizagem. Assim, parte das interações e comunicações pode acorrer de forma síncrona (professor e aluno interagem em tempo real) e de forma assíncrona (quando não há interação em tempo real). As diferentes metodologias de ensino e aprendizagem utilizadas na EaD buscam a geração de conhecimentos e elaboração por parte dos acadêmicos, o acompanhamento e a avaliação da aprendizagem.

Esse estudo objetivou, analisar a metodologia de aprendizagem baseada em projeto, desenvolvida na disciplina de Seminário Temático I, no Curso de Tecnologia em Gestão Comercial (TGC) na modalidade a Distância, de uma universidade de Santa Catarina. Assim, se propõe a apresentar a experiência de ensino da disciplina que ocorre na terceira fase do curso e apresenta como premissas o desenvolvimento de um diagnóstico da área comercial, realizado em grupo.

\footnotetext{
${ }^{1}$ UNESC, michele.schneider@unesc.net

2 UNESC, enz@unesc.net

3 UNESC, nara@unesc.net
} 
Os objetivos específicos tangem a descrição da metodologia empregada na disciplina; apresentação da avaliação por partes dos acadêmicos com relação ao desempenho docente, a avaliação dos recursos e materiais didáticos da disciplina e a auto-avaliação discente, bem como destacar os pontos fortes e fracos encontrados no decorrer da disciplina.

\title{
EDUCAÇÃO A DISTÂNCIA
}

A EaD é uma modalidade de educação que se efetiva pelo uso intenso das TICs, possibilitando a interação de alunos e professores em ambientes virtuais de aprendizagem (AVA). Eles podem estar separados no tempo e espaço, com atividades pedagógicas sendo desenvolvidas de forma síncronas e assíncronas (MORAN, 2002).

Alves (2011) conceitua $\mathrm{EaD}$ como uma forma sistematizada de educação onde o aluno organiza seus estudos, de acordo com os roteiros e atividades propostas, orientadas e supervisionadas por professores e tutores, que usam recursos das TICs para mediar esses processos orientadores e avaliativos, vencendo dessa forma as condicionantes de tempo e distância.

No Brasil, a EaD é definida no Decreto n. 5.622 de 2005 (BRASIL, 2005, p. 1):

\begin{abstract}
Art. 1o Para os fins deste Decreto, caracteriza-se a Educação a Distância como modalidade educacional na qual a mediação didático-pedagógica nos processos de ensino e aprendizagem ocorre com a utilização de meios e tecnologias de informação e comunicação, com estudantes e professores desenvolvendo atividades educativas em lugares ou tempos diversos.
\end{abstract}

Alves (2011, p.90) destaca que: "[...] a Educação a Distância oferece oportunidades que pelo modelo presencial seria difícil ou impossível de atingir, pois possui uma ampla abrangência e grandiosa magnitude não somente no nosso país, mas em todo o mundo." Enfatiza que a EaD é considerada a forma mais democrática de educação, por possibilitar o acesso ao conhecimento, àqueles que não teriam oportunidades no ensino presencial, seja em função de valores monetários, tempo e/ou distância. 


\section{EAD NO BRASIL}

Historicamente, pode-se definir como marco inicial para a EaD no mundo, o século XVIII, tendo suas origens em 1728, quando da oferta de um curso pela Gazeta de Boston, que tinha como base a disponibilização de materiais para ensino por correspondência. Mas, tratava-se de ações isoladas; somente no século XIX que surge institucionalmente a EaD (VASCONCELOS, 2010; GOUVEA; OLIVEIRA, 2006).

No Brasil, os primeiros registros de EaD apontam para 1904, como o marco no país, quando o Jornal do Brasil anuncia em seus classificados um curso de profissionalização de datilógrafo por correspondência (MAIA; MATTAR, 2007).

Segundo dados do Censo MEC 2011-2012, a EaD é a modalidade de educação que vem ganhando cada vez mais espaço, pois o número de alunos matriculados já representa cerca de $20 \%$ do número total de alunos matriculados no ensino superior. É a modalidade de ensino que cresceu três vezes mais que o ensino presencial.

Alves (2011) destaca que a EaD no Brasil vem evoluindo e ganhando mais adeptos a cada ano, porém, ainda existem possibilidades para maiores avanços, a fim de que a EaD alcance lugar de destaque no meio educacional. Nesse sentido, o autor destaca alguns pré-conceitos com relação à EaD no Brasil, relacionados a concepção de que: cursos a distância não apresentam padrões de qualidade; dificuldades nos critérios de avaliação relacionados a subjetividade; falta de padrões de controle do aprendizado; entre outros.

Para regulamentar e estabelecer critérios para qualidade dos cursos a distância, o Governo Federal estabeleceu normas e leis que devem ser seguidas pelas instituições de ensino que atuam nessa modalidade, sendo que os diplomas possuem equivalência aos cursos presenciais (UNIFESP, 2009).

\section{APRENDIZAGEM BASEADA EM PROJETOS}

Teixeira et al (2006) discorrem sobre as mudanças no contexto do ensino que resultaram em alterações nos currículos, a fim de atender às novas exigências do 
mercado, para possibilitar à universidades colocar no mercado, profissionais com habilidades e competências diferenciadas. Os mesmos autores definem a aprendizagem baseada em projetos (ABP), como uma metodologia de ensino que foca na organização do aprendizado em uma estrutura de projeto. Implica em sistematizar os conhecimentos, com o desenvolvimento de atividade investigativa, de tarefas complexas, resolução de problemas e processos de tomada de decisão. Ressaltam que a base da $A B P$ dá-se por meio de dois pontos da teoria cognitiva que perpassam 0 trabalho de problemas significativos e despertam no aluno a busca por informações adicionais, gerado autonomia e aprendizagem.

A metodologia de ABP tem suas origens apontadas por volta de 1900, com o filósofo americano John Dewey. Dewey constata em seus experimentos que o processo de aprendizado é potencializado pelo ato de aprender a fazer. Desenvolve-se a ABP pela contextualização de problemas ou situações do cotidiano profissional. O aluno é incentivado a desenvolver habilidades e competências aliadas aos conhecimentos desenvolvidos nas disciplinas para o entendimento, reflexão e questionamentos sobre os conteúdos estudados (MASSON et al, 2012).

De acordo com Campos (2011), a ABP tem sido popularizada pela possibilidade de elaboração dos currículos e utilização de práticas inovadoras de aprendizagem, além da abordagem de aprendizagem ativa. Nessa abordagem, o professor assume um papel diferente dos processos tradicionais, o aluno torna-se o centro do processo e assume papel ativo na sua própria aprendizagem. Masson et al (2012, p.3) destacam como principais características da ABP: "o aluno é o centro do processo; desenvolve-se em grupos tutoriais; caracteriza-se por ser um processo ativo, cooperativo, integrado e multidisciplinar e orientado para a aprendizagem do aluno".

Nesse sentido, o aluno é incentivado a pesquisar e resolver as situações apresentadas, apropriando-se dos conceitos científicos, com o professor assumindo papel de moderador. Na busca de informações e nas atividades em grupo, desenvolve habilidades para trabalhar em equipe, mediar e resolver conflitos e, a autonomia (MASSON et al, 2012).

\section{PROCEDIMENTOS METODOLÓGICOS}


Os procedimentos metodológicos empregados no estudo de caso utilizam a pesquisa descritiva e exploratória, pois o pesquisador, ao observar os fenômenos, busca conseguir resultados ao término da pesquisa, que permitam o entendimento destes fenômenos (FACHIN, 2003). Objetivou-se na pesquisa, analisar a metodologia de aprendizagem baseada em projeto, desenvolvida na disciplina de Seminário Temático I, no Curso de Tecnologia em Gestão Comercial (TGC) na modalidade a Distância. Descreve-se a metodologia, ementa e procedimentos didático-pedagógicos, os quais norteiam o planejamento e execução da disciplina em estudo.

Nas estratégias de investigação aplicadas na pesquisa utilizou-se de métodos mistos, no enfoque de pesquisa quali-quantitativa, de acordo com a complexidade do objeto. A estratégia mista permite aplicação simultânea dos métodos qualitativos e quantitativos, proporcionando um efeito transformador ao objeto (CRESWEL, 2007). As estratégias selecionadas passam por pesquisa documental, com a utilização de dados secundários disponíveis ao pesquisador e estudo de caso, pois permite o conhecimento do objeto de pesquisa de fora mais ampla e detalhada (GIL, 1999).

A abordagem da pesquisa é quali-quantitativa, de forma que o pesquisador se propõe a estudar o objeto, e entender as inter-relações do mesmo com o meio em que está inserido, no sentido de buscar o entendimento de como a disciplina se constitui e como é percebida pelos estudantes. A pesquisa qualitativa possibilita a exploração, a descrição da complexidade do tema e problema de pesquisa de forma que possa permitir ao pesquisador a análise, compreensão, classificação para a geração de contribuições aos indivíduos envolvidos e ao objeto de pesquisa. Analisa-se também a partir de dados quali-quantitativos, os resultados obtidos na avaliação institucional, realizada com os acadêmicos da terceira fase do curso, semestre 2015-1. O instrumento de avaliação foi aplicado no período de 22/06 à 14/07/2015. A amostra foi composta por vinte e nove acadêmicos da disciplina.

\section{APRESENTAÇÃO E ANÁLISE DOS RESULTADOS}


A disciplina de Seminários Temático I, do Curso de TGC na modalidade a distância, tem como ementa: "execução e apresentação do estudo de caso aplicado na área de abrangência do curso", tendo como objetivo geral, proporcionar ao acadêmico identificar em uma empresa real como estão dispostas e organizadas as suas estruturas comerciais, relacionando à teoria e prática na identificação de cenários, proporcionando subsídios para elaboração de diagnóstico empresarial. Os objetivos específicos da disciplina são: identificar a estrutura comercial em uma empresa; avaliar as ferramentas de marketing utilizadas na empresa; avaliar a efetividade das ferramentas de comunicação utilizadas na empresa em estudo; relacionar teoria e prática e integrar dos conhecimentos das disciplinas.

A ABP da disciplina em estudo baseia-se na elaboração de um projetodiagnóstico da área comercial de empresas escolhidas pelos próprios acadêmicos, os quais se organizam em grupos e desenvolvem as atividades a distância. Como citam Masson et al (2012) na ABP, as ações em grupos tutorias, devem promover processos ativos, cooperativos, integrados e multidisciplinar com foco na aprendizagem dos acadêmicos. A elaboração do diagnóstico é baseada em um tutorial desenvolvido pelo professor para a disciplina, dividido em etapas, organizado em temas de estudo. As aulas online são semanais num período de 18 semanas. Em cada etapa desenvolvida a distância os acadêmicos são avaliados. Em algumas das etapas do estudo, as atividades são desenvolvidas de forma interdisciplinar com outras disciplinas do curso, como: Comunicação em Vendas e, Estatística. Ao final da disciplina, os acadêmicos apresentam o relatório com o diagnóstico e as etapas desenvolvidas ao longo do semestre que se caracteriza como uma avaliação presencial. A apresentação é registrada em vídeo, para que se mantenha o registro da avaliação presencial.

A disciplina Seminário Temático I foi desenvolvida sob a ótica de apresentar e desenvolver uma temática, de forma a possibilitar aos acadêmicos, refletir sobre o "Ser Gestor Comercial". Para tanto, são discutidos alguns textos e, posteriormente, iniciam-se os estudos do diagnóstico. O desenvolvimento de atividade investigativa, de tarefas complexas, resolução de problemas e processos de tomada de decisão são características fundamentais da metodologia de ABP, como citam Teixeira et al (2006). 
Observou-se no processo inicial, dificuldades na realização de atividades distância em grupo que foram sanadas no processo.

Apresenta-se a seguir, a estrutura da organização do projeto-diagnóstico desenvolvido na disciplina, organizado em nove etapas, das quais, três contemplam atividades interdisciplinares.

Na primeira etapa, ocorre o levantamento dos dados históricos da empresa com a finalidade é conhecer sua história, evolução e, identificar os aspectos que compreendem a cultura organizacional, missão, visão, valores e a definição do negócio.

$\mathrm{Na}$ segunda etapa, efetua-se o levantamento dos dados referentes á estrutura comercial: organograma e hierarquia, descrição da estrutura da área, composição da equipe de vendas, contendo quantidade $e$ área de atuação, identificação se as vendas são internas ou externas e se os vendedores são funcionários da empresa ou representantes comerciais.

A terceira etapa refere-se a análise do Macro e Microambiente, com objetivo de compreender os impactos e influencias do Macro e microambiente nas estratégias e posicionamento da empresa. A análise do Macroambiente consiste em análise do Ambiente Social, demográfico, político-legal, econômico, tecnológico e concorrência. A análise do Microambiente externo ocorre com olhar para o mercado, acionistas, intermediários de marketing, fornecedores. E, a análise dos componentes do Microambiente interno deve conter a análise de recursos humanos, financeiros, produção, pesquisa e desenvolvimento, localização e imagem da empresa.

A quarta etapa consiste na análise das Estratégias Mercadológicas utilizadas pela Empresa em estudo, nessa etapa os acadêmicos apresentam de que forma a empresa desenvolve o composto mercadológico (4P's do Marketing). São apresentadas as estratégias utilizadas para produto, preço, praça e promoção.

$\mathrm{Na}$ sequência (quinta etapa), são desenvolvidas atividades com objetivo de identificar e avaliar as ferramentas de Comunicação Mercadológica utilizadas pela empresa em estudo, tais como ações de Propaganda, Promoção de Vendas, Merchandising, Relações Públicas e Venda Pessoal. Nessa etapa, a atividade é desenvolvida de forma interdisciplinar com a disciplina de Comunicação em Vendas do 
referido curso. O relatório desenvolvido é avaliado nas duas disciplinas e são feitas em conjunto pelos professores das mesmas.

$\mathrm{Na}$ etapa seis, são avaliadas as Estratégias de Desenvolvimento de Novos Produtos e de que forma esses processos acontecem nas empresas estudadas. Devem ser observados os processos de geração e seleção de ideias, desenvolvimento e teste de conceito, desenvolvimento de estratégias de marketing, análise de negócio, desenvolvimento de produto, teste de mercado e comercialização dos novos produtos.

$\mathrm{Na}$ sétima etapa, efetua-se a análise das Estatísticas de Venda dos produtos compreendendo o levantamento das vendas de cinco (5) produtos comercializados pela empresa no período de três (3) meses. Com base nos levantamentos são desenvolvidos gráficos, tabelas e análises relativas a estáticas de vendas, como tendência, variação e desvio padrão. Essa é outra atividade interdisciplinar que é realizada com a disciplina de estatística do curso.

$\mathrm{Na}$ oitava etapa são desenvolvidas atividades relativas á Administração da Força de Vendas que é interdisciplinar. Nesta fase é identificado: o tamanho da força de vendas (quantas pessoas internas e quantas externas em vendas são vendedores contratados pela empresa de acordo com as normas da CLT (Consolidação das Leis Trabalhistas) ou são representantes comerciais): as filiais e os CDs (centros de distribuição), pois, em alguns casos, também fazem parte da força de vendas; o tamanho da carteira de clientes. Investiga-se também, o plano de remuneração da empresa - se é salário fixo, fixo mais variável (comissão) ou, 100\% variável (comissão); região de atuação; as tecnologias usadas pela força de vendas que contribuem na agilidade e no incremento de vendas da empresa; o levantamento de quais as medidas e estratégias de "pós-vendas" a empresa adota para dar suporte ao cliente/consumidor.

A nona e última atividade da disciplina refere-se à elaboração de sugestões de melhorias. Para a proposição das sugestões, os acadêmicos são orientados a utilizar a análise de SWOT com identificação de pontos fortes, pontos fracos, ameaças e oportunidades. Essa análise utiliza-se dos dados levantados nas etapas anteriores, gerando sugestões de melhorias embasadas e fundamentadas nos dados coletados.

$\mathrm{Na}$ conclusão das etapas, os trabalhos são apresentados em forma de Seminário pelos grupos, registrados em vídeo, compreendendo a avaliação presencial. 
Como cita Masson, et al. (2012), ao pesquisar e buscar informações para resolver as situações apresentadas nas atividades em grupo, o acadêmico desenvolve autonomia, competências e habilidades para trabalhar em equipe, mediar e resolver conflitos.

Os resultados alcançados com a disciplina são relevantes pela qualidade das produções e consistência dos dados apresentados. Vale ressaltar que, num primeiro momento, quando a disciplina é apresentada, observa-se certa resistência por parte dos acadêmicos, em realizar atividades em grupo e a distância, as quais ao longo do semestre vão diminuindo.

Ao término de cada disciplina, os acadêmicos participam da avaliação institucional organizada em três blocos: autoavaliação discente; avaliação do material e recursos didáticos; avaliação do desempenho docente. Os indicadores de avaliação são: MS (Muito satisfeito); S (Satisfeito); PS (Parcialmente satisfeito); I (Insatisfeito); MI (Muito insatisfeito); NA (Não sei avaliar); NR (Não respondeu). A partir destes indicadores é estabelecida uma média ponderada com pontuação de 0 a 10.

Analisando os resultados do bloco I, observa-se que, com relação ao cumprimento das atividades a distância, os acadêmicos avaliam-se com média geral 8,0. A participação ativa nas atividades propostas pelo professor é avaliada pelos acadêmicos com menor nota na seção, representando 7,92. A utilização de outras fontes, além das indicadas no ambiente virtual pelo professor, obteve média ponderada 8,0. No desenvolvimento do projeto-diagnóstico, os acadêmicos necessitam fundamentar os pontos desenvolvidos e, para tanto, além das referências básicas e complementares, são incentivados a utilizar outras fontes, como os livros das demais disciplinas disponíveis na biblioteca, bases de dados e fontes confiáveis da internet.

A segunda seção refere-se à avaliação do material e recursos didáticos utilizados na disciplina como as aulas com webconferência, o material didático, a estrutura da sala virtual e o atendimento da monitoria. Na avaliação da qualidade do material didático, a média ponderada ficou em 7,69. Nesse quesito, vale ressaltar que, diferente das demais disciplinas do curso de TGC, na disciplina de Seminário Temático I utiliza-se de tutorial disponibilizado no AVA ao invés de material didático impresso (livro). 
Com relação à qualidade do material didático digital (videoaula), a média ponderada aponta para nota 8,14 . Vale ressaltar que nas videoaulas são explicitadas as atividades a serem desenvolvidas e os feedbacks das correções dos trabalhos. São gravadas e disponibilizadas no AVA após a edição e tratamento das imagens. Sobre a avaliação da linguagem do conteúdo do material didático, foi obtida média 8,0. A articulação entre as atividades e o conteúdo do material didático, é avaliada com média 7,69. O indicador de qualidade da Webconferência é o quesito com menor desempenho, com a média 7,43. Tem relação direta com os problemas relacionados a transmissão de dados na rede Internet - lentidão, congelamento de imagem, cortes no som, entre outros. O atendimento da monitoria foi melhor avaliado, com média de 8,75.

A terceira seção refere-se à avaliação do desempenho docente, sendo avaliado em diversos indicadores. Sobre o cumprimento do cronograma/agenda estabelecido para a disciplina, a média ponderada ficou em 8,62. O uso de linguagem clara e objetiva pelo docente é avaliado com média 8,23. A organização da sala virtual (roteiros de aprendizagem, videoaulas, atividades) é avaliada com nota 8,08. Vale destacar que as salas virtuais do curso têm a mesma estrutura e organização, com objetivo de criar uma identidade do curso e permitir que o acadêmico se localize facilmente no ambiente virtual. $\mathrm{Na}$ avaliação sobre à articulação teoria e prática no desenvolvimento dos conteúdos por parte do docente, os acadêmicos pontuaram em 8,54. Quanto ao esclarecimento de dúvidas pela tutoria no decorrer da disciplina, a média ficou em 8,61.

Com base nos dados apresentados, pode-se afirmar que, os acadêmicos avaliam positivamente a proposta didático-pedagógica da disciplina, cuja metodologia é a ABP. Obtevese 8,16 na média ponderada do bloco I; 8,75 na média do bloco II; e, 8,41 na média ponderada do bloco III. Neste último, 59,31\% afirmam estar satisfeitos e muito satisfeitos com a atuação do docente, que na metodologia de ABP, segundo Masson, et al. (2002) assume a função de moderador no processo de aprendizagem do acadêmico.

\section{CONSIDERAÇÕES FINAIS}


A EaD cresce de forma acentuada no Brasil e apresenta barreiras, resistências e dificuldades nesse processo de expansão. Entretanto, apresenta-se como a modalidade de educação que amplia o acesso democrático ao ensino superior. $\mathrm{Na}$ pesquisa, efetuou-se a análise da metodologia de $\mathrm{ABP}$, da disciplina de Seminário Temático I, no Curso de TGC - modalidade a distância. A mesma ocorre por meio da elaboração de um projeto-diagnóstico comercial em empresas situadas no mercado regional, selecionadas pelos estudantes, organizados em grupos pelo professor. São desenvolvidas nove (9) atividades, sendo que três (3) são interdisciplinares. Estas últimas acontecem de forma concomitante com as demais disciplinas do curso que abordam esses conteúdos, o que permite ao acadêmico observar na prática, como as teorias fazem-se presentes no cotidiano das empresas estudadas.

Para contribuir na analise dos dados da pesquisa, incluíram-se os indicadores da avaliação institucional com o objetivo de verificar a percepção do acadêmico sobre a proposta pedagógica da disciplina e o seu desenvolvimento. A autoavaliação discente aponta para um alto nível de satisfação com o seu próprio desempenho, com 8,16 na média ponderada. 70,53\% consideram-se MS (Muito satisfeito) e $S$ (Satisfeito) com sua atuação, empenho e participação nas atividades propostas pelo professor. A média geral do bloco Avaliação do material e recursos didáticos foi de 8,75 com posicionamento de MS e S em $67,86 \%$ dos acadêmicos. Na avaliação do Desempenho docente, $75,71 \%$ dos estudantes consideram-se satisfeitos e muito satisfeitos, sendo essa a seção melhor avaliada com média ponderada de 8,41 pontos. Essa pontuação se dá em grande parte pelo atendimento do cronograma das aulas e esclarecimentos das dúvidas dos estudantes na tutoria da disciplina.

Conclui-se que, na ótica discente, a disciplina é bem avaliada, com altos índices de estudantes satisfeitos e muito satisfeitos. Alguns relatos dos estudantes apontam para as dificuldades de realização de atividades em grupo devido à gestão do tempo e demandas de informações necessárias para o desenvolvimento das atividades. Ao professor, as dificuldades vêm do volume de produção gerado pelas atividades e a necessidade de correções, devoluções e reavaliações, resultando um excesso de carga de trabalho. Como pontos fortes, podem-se destacar a qualidade das produções dos acadêmicos, a gestão dos trabalhos em equipe e a distância, o desenvolvimento da 
capacidade de mediação e resolução de conflitos em seu decorrer, o comprometimento e participação das atividades propostas e a capacidade desenvolvida nos estudantes de relacionar a teoria com a prática.

\section{REFERÊNCIAS}

ALVES, Lucineia. Educação a Distância: Conceitos e História no Brasil e no Mundo. In: Anais do CIEAD. Volume 10, Curitiba/PR: ABED, 2011.

BRASIL. Decreto 5.622, de 19 de dezembro de 2005. Diário Oficial [da] República Federativa do Brasil. Brasília, DF, 20 dez. 2005. Disponível em: < http://www.planalto.gov.br/ccivil_03/_ato2004-2006/2005/decreto/d5622.htm>. Acesso em: 25 mai. 2015.

CAMPOS, L.C., Aprendizagem Baseada em Projetos: uma nova abordagem para a Educação em Engenharia. In: COBENGE 2011, Blumenau, SC, 3 a 6/10/2011.

CRESWELL, J. W. Projeto de Pesquisa: métodos qualitativo, quantitativo e misto. Porto Alegre: Artmed Bookman, 2007.

FACHIN, O. Fundamentos de metodologia. 4.ed. São Paulo: Saraiva, 2003.

GIL, A.C. Métodos e técnicas de pesquisa social. 5.ed. São Paulo: Atlas, 1999.

GOUVÊA, G.; OLIVEIRA, C. I. Educação a Distância na formação de professores:

viabilidades, potencialidades e limites. 4. ed. Rio de Janeiro: Vieira e Lent. 2006.

MAIA, C.; J. MATTAR. ABC da EaD: a Educação a Distância hoje. 1. ed. São Paulo: Pearson. 2007.

MASSON, T.J.; MIRANDA, L.F; MUNHOZ JR, A.H.; CASTANHEIRA, A.M.P. Metodologia de Ensino: Aprendizagem baseada em Projetos ( $A B L)$. Anais do XI Congresso Brasileiro de Ensino de Engenharia, 2012.

MORAN, J. M. O que é Educação a Distância. Universidade de São Paulo, 2002. Disponível em: < http://www2.eca.usp.br/moran/wp-content/uploads/2013/12/dist.pdf>. Acesso em: 14 mai. 2015. 
TEIXEIRA, F.G; SILVA, R.P.; SILVA, T.L.K; HOFFMANN, A.T. Geometria Descritiva: aprendizagem baseada em projetos. Anais do XXXIV Congresso Brasileiro de Ensino de Engenharia, 2006.

UNIFESP Virtual. Educação a Distância: fundamentos e guia metodológico. Disponível em <http:// www.virtual.epm.br/home/resenha.htm>. Acesso em: 25 mai. 2015.

VASCONCELOS, S. P. G. Educação a Distância: histórico e perspectivas. Universidade do Estado do Rio de Janeiro (UERJ). Disponível em: < http://www.filologia.org.br/viiifelin/19.htm >. Acesso em: 08 jan. 2010. 